\title{
Sparstolonin B attenuates spinal cord injury-induced inflammation in rats by modulating TLR4-trafficking
}

\author{
JIANJUN YUAN, XUELI ZHANG, RUSEN ZHU, ZIJIAN CUI and WEI HU \\ Department of Spine Surgery, Tianjin Union Medical Center, Tianjin, Hongqiao 300121, P.R. China
}

Received November 29, 2016; Accepted September 22, 2017

DOI: $10.3892 / \mathrm{mmr} .2018 .8561$

\begin{abstract}
The present study used a spinal cord injury (SCI) model to evaluate whether sparstolonin B was able to prevent SCI, and to investigate the underlying signaling mechanism. Sparstolonin B attenuated the SCI-induced Batto, Beattie and Bresnahan score and water content in rats. Sparstolonin B attenuated the mRNA expression of proinflammatory cytokines interleukin (IL)-18, IL-6, IL-1 $\beta$, and IL-23, decreased the levels of tumor necrosis factor- $\alpha$ and interferon- $\gamma$, and decreased caspase-3 activity and apoptosis regulator Bax protein expression in SCI rats. Similarly, sparstolonin B inhibited monocyte chemoattractant protein-1 mRNA levels, and Toll-like receptor (TLR) 4, myeloid differentiation primary response protein MyD88 (MyD88) and nuclear factor (NF)- $\mathrm{B}$ protein levels in SCI rats. The present results suggested that sparstolonin B may attenuate SCI-induced inflammation and apoptosis in rats by modulating the TLR4/MyD88/NF- $\mathrm{B}$ signaling pathway.
\end{abstract}

\section{Introduction}

Spinal cord injury (SCI) is a clinically-common form of accidental damage, due to the development of the social economy and increasing use of motor vehicles. Cases of SCI caused by work and traffic accidents are increasing (1). It has been reported that there are $>300,000$ new cases of SCI worldwide every year, predominantly in young adults (2). However, no accurate statistics are available in China at present. Data published in 2013 indicated that the number of patients with SCI patients totaled $>1,000,000$, with an average annual increase of 10,000 (3). The treatment of SCI is difficult and is associated with high rates of disability (3). SCI represents a psychological and economic burden for patients, their families and society. The treatment of SCI has been a focus of research

Correspondence to: Dr Xueli Zhang, Department of Spine Surgery, Tianjin Union Medical Center, 190 Jieyuandao, Tianjin, Hongqiao 300121, P.R. China

E-mail: yongmshcaz@163.com

Key words: sparstolonin B, spinal cord injury, inflammation, Toll-like receptor 4 worldwide (4). Existing clinical treatment methods for SCI include surgical decompression, topical drugs, acupuncture, local cryoablation, connective tissue and scarring elimination, and physical rehabilitation. Although these treatments may be effective, a number of long-term neurological sequelae may occur $(4,5)$.

SCI encompasses primary and sequential damage. The primary damage is instant and irreversible, and may directly lead to cell death at the site of injury. Effective intervention may be challenging to deliver in the clinic (6). Sequential injury occurs within several h or days, primarily as chronic reactive damage to the spinal cord (7). In addition, the injury may progress in a sustained manner (8). Sequential SCI causes more severe damage to the spinal cord compared with primary injury (9). The sequential injury mechanisms of the spinal cord primarily include inflammatory reactions, neurogenic shock, cellular apoptosis, excitatory poisoning, mitochondrial dysfunction, free radicals and reperfusion injury (10).

Toll-like receptors (TLRs) are a type of pattern recognition receptor, which were originally detected in Drosophila embryos (11). Subsequently, homologous receptors were identified in mammals. These receptors are collectively known as the TLR family. It has been determined that the TLR family includes at least 12 members (12). TLRs are extensively distributed on the surface of macrophages, monocytes, dendritic cells, natural killer cells and lymphocytes (12). The TLR4 signal pathway has been extensively studied, due to its role in mediating inflammatory reactions (13). Previous studies have demonstrated that microglial cells express TLR1-TLR9, primarily TLR4; it was identified through culturing of neuronal cells, microglial cells, oligodendrocytes and astrocytes taken from the prosencephalon of neonatal mice that TLR4 is highly-expressed on the surface of microglial cells $(14,15)$.

Scirpus yagara is classified as a small grass in the family Cyperaceae; it is the dry lotus of S. fluviatilis (Torr.) A. Gray (S.yagara Ohwi) (14). S. yagara is bitter in taste and is believed to exhibit pharmacological functions, following the principles of traditional Chinese medicine, including alleviating stagnated blood, promoting the circulation of qi, and relieving dyspepsia and pain (15). S. yagara may be applied to the treatment of abscesses, congestion, amenorrhea and pain associated with dyspepsia (16). Sparstolonin B (Fig. 1) is a novel oxygen-mixed anthracene compound detected in a traditional Chinese medicine, Sparganium stoloniferum (15), and is additionally present in S. yagara. A previous study demonstrated that 
sparstolonin B is a low-toxicity TLR2 and TLR4-selective antagonist, which is able to inhibit inflammation induced by lipopolysaccharide in in vivo mouse models (16). Therefore, sparstolonin $\mathrm{B}$ has been hypothesized to be a potential novel treatment for inflammation and associated diseases (17). In the present study, the potential protective effect of sparstolonin B against inflammation and apoptosis in an SCI model was examined, and the molecular mechanism underlying the effects of sparstolonin B in SCI was investigated by studying alterations in TLR4 signaling pathways.

\section{Materials and methods}

Ethics and animals. Male Sprague-Dawley rats ( $\mathrm{n}=30$; weight, 200-230 g; age, 6 weeks) were purchased from Experiment Center of Tianjin Medical University (Tianjin, China) and were housed under standard environmental conditions (humidity, 45-55\%; temperature, $22-23^{\circ} \mathrm{C}$, 7-h light/19-h dark cycle) and maintained on a normal rodent diet and tap water ad libitum. The present study was approved by the institutional Animal Care and Use Committee of Tianjin People's Hospital (Tianjin, China) and was performed according to the principles of the National Institutes of Health Guide for the Care and Use of Laboratory Animals (National Institutes of Health, Bethesda, MD, USA).

Rats were anesthetized using xylazine hydrochloride $(5 \mathrm{mg} / \mathrm{kg}$ ) and ketamine hydrochloride $(75 \mathrm{mg} / \mathrm{kg})$. The back of each rat was cleaned with povidone iodine (10\%) and a laminectomy was performed at T9-T11 to expose the underlying T10 spinal cord, following a dorsomedial incision to the skin. The spinal cord was exposed and the paravertebral muscles were dissected bluntly, exposing the lamina bilaterally. A complete laminectomy was performed at T9-T11, and the SCI model was induced at the T10 segment using an aneurysm clip (Yasargil FE 760; Aesculap, Inc., Corporate Parkway, PA, USA), applied extradurally for $30 \mathrm{sec}$. The aneurysm clip was subsequently removed, and the fascia and skin were sutured separately using silk stitches.

Experimental groups. The rats were randomly divided into three groups: Group 1, the control group $(n=6)$, comprised normal rats treated with PBS; group 2, the SCI model group $(n=12)$, comprised SCI model rats treated with PBS; group 3, the sparstolonin B group $(n=12)$, comprised SCI model rats treated with $300 \mathrm{mg} / \mathrm{kg}$ sparstolonin B (Sigma-Aldrich; Merck KGaA, Darmstadt, Germany) every other day for 4 weeks.

Basso, Beattie and Bresnahan (BBB) score and water content. Following treatment with sparstolonin $B$, the rats were assessed for functional recovery using the BBB Locomotor Rating Scale (18) and carried out by two independent reviewers. Following sparstolonin $\mathrm{B}$ treatment, rats were sacrificed using decollation under $35 \mathrm{mg} / \mathrm{kg}$ of pentobarbital sodium. The abdomens of the rats were cut open, spinal level T10 was peeled and spinal cord tissues were collected and washed with PBS. Spinal cord tissues were weighed as wet weight, then spinal cord tissue was heated at $68^{\circ} \mathrm{C}$ for $72 \mathrm{~h}$, and weighed as dry weight. The water content of spinal cord tissue was calculated by (wet weight/dry weight) $\mathrm{x} 100$.

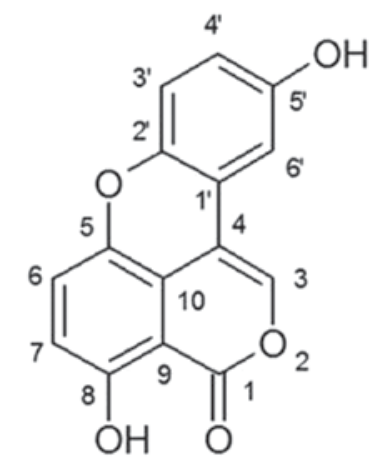

Figure 1. Structural formula of sparstolonin B.

ELISA. Following treatment with sparstolonin B, rats were sacrificed by decollation as above and the spinal cord acquired. Tissue samples (50 mg) were homogenized and dissociated in radioimmunoprecipitation assay lysis buffer (BestBio Biotechnology, Shanghai, China) for $30 \mathrm{~min}$ on ice. The supernatants were collected following centrifugation at $10,000 \mathrm{x} \mathrm{g}$ for $10 \mathrm{~min}$ at $4^{\circ} \mathrm{C}$ and used to measure total protein using bicinchoninic acid (BCA) buffer (BestBio Biotechnology). Protein (10 $\mu \mathrm{g})$ was used to measure TNF- $\alpha$ (E-EL-R0019c) and IFN- $\gamma($ E-EL-R0009c) levels using ELISA kits (Elabscience, Wuhan, China).

Reverse transcription-quantitative polymerase chain reaction (RT-qPCR) analysis. Following treatment with sparstolonin B, rats were sacrificed and the spinal cord acquired as above. Total RNA was extracted from tissue samples using TRIzol reagent (Thermo Fisher Scientific, Inc., Waltham, MA, USA). Total RNA (500 ng) was used for reverse transcription into cDNA using a First-strand cDNA Synthesis kit (Bio-Rad Laboratories, Inc., Hercules, CA, USA). qPCR was performed using iQ SYBR Green Supermix (Bio-Rad Laboratories, Inc.) on an Eppendorf Realplex2 Mastercycler (BioRad Laboratories, Inc.). qPCR was performed under the following conditions: $95^{\circ} \mathrm{C}$ for $10 \mathrm{~min}$, followed by 40 cycles of $95^{\circ} \mathrm{C}$ for $20 \mathrm{sec}, 58^{\circ} \mathrm{C}$ for $25 \mathrm{sec}$ and $72^{\circ} \mathrm{C}$ for $30 \mathrm{sec}$. The miRNA expression was analyzed using the $2^{-\Delta \Delta \mathrm{Cq}}$ method (19).

Western blot analysis. Tissue samples (50 mg) were homogenized and dissociated in radioimmunoprecipitation assay lysis buffer (BestBio Biotechnology, Shanghai, China) for $30 \mathrm{~min}$ on ice. The supernatants were collected following centrifugation at $10,000 \mathrm{x}$ g for $10 \mathrm{~min}$ at $4^{\circ} \mathrm{C}$ and used to measure total protein using bicinchoninic acid (BCA) buffer (BestBio Biotechnology). Proteins $(50 \mu \mathrm{g})$ were separated using SDS-PAGE on $8-10 \%$ gels and transferred onto polyvinylidene fluoride membranes. Membranes were blocked with Tris-buffered saline with Tween-20 (TBST) for $1 \mathrm{~h}$ at $37^{\circ} \mathrm{C}$ and subsequently immunoblotted with anti-tumor necrosis factor (TNF)- $\alpha$ (sc-8301; 1:500), interferon (IFN)- $\gamma$ (sc-393089; 1:500), apoptosis regulator Bax (Bax; sc-6236; 1:500), TLR4 (sc-10741; 1:500), myeloid differentiation primary response protein MyD88 (MyD88; sc-11356; 1:500), nuclear factor (NF)- $\mathrm{B}$ (sc-109; 1:500) and GAPDH (sc-25778; 1:500; all from Santa Cruz Biotechnology, Inc., Dallas, TX, USA) at $4^{\circ} \mathrm{C}$ overnight. The membrane was washed with TBST and incubated with goat anti-rabbit or anti-mouse 

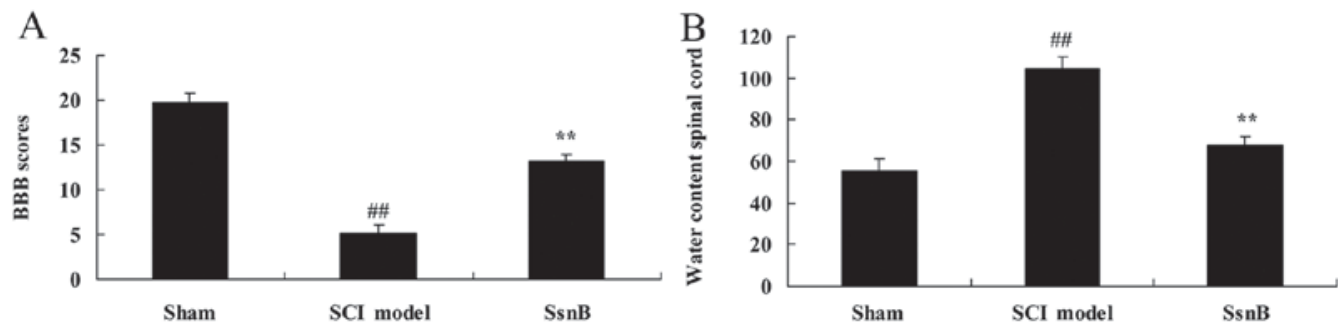

Figure 2. Sparstolonin B attenuates the SCI-induced BBB score and water content in rats. Sparstolonin B attenuated the SCI-induced (A) BBB score and (B) spinal water content in rats. ${ }^{\# \#} \mathrm{P}<0.01$ vs. sham control group; ${ }^{* *} \mathrm{P}<0.01$ vs. SCI model group. SsnB, sparstolonin B group; SCI, spinal cord injury; BBB score, Batto, Beattie and Bresnahan score.

IgG-horseradish peroxidase conjugated secondary antibody (sc-2004 and sc-2005; 1:5,000; Santa Cruz Biotechnology, Inc.) at room temperature for $1 \mathrm{~h}$ with agitation. The membrane was observed using BeyoECL Plus (Beyotime Institute of Biotechnology, Haimen, China) and analyzed using Image Lab Software version 3.0 (Bio-Rad Laboratories, Inc.).

Caspase- 3 activity. Tissue samples $(20 \mathrm{mg}$ ) were homogenized and dissociated in radioimmunoprecipitation assay lysis buffer (BestBio Biotechnology) for $30 \mathrm{~min}$ on ice. The supernatants were collected following centrifugation at $10,000 \mathrm{x} \mathrm{g}$ for 10 min at $4^{\circ} \mathrm{C}$ and used to measure total protein using BCA buffer (BestBio Biotechnology). Protein (10-20 $\mu \mathrm{g}$ ) was incubated with Ac-DEVD-pNA ( $2 \mathrm{mM}$; BestBio Biotechnology) for $1 \mathrm{~h}$ at $37^{\circ} \mathrm{C}$. Absorbance values for caspase- 3 activity were measured at $405 \mathrm{~nm}$.

Immunohistochemistry. Following treatment with sparstolonin B, rats were sacrificed using decollation and the spinal cord acquired as above. The spinal cords were fixed in $4 \%$ paraformaldehyde for $24 \mathrm{~h}$ at room temperature. Tissue samples were cryoprotected in $30 \%$ sucrose in $0.1 \mathrm{M}$ phosphate buffer with $0.01 \%$ sodium azide and sectioned at $15 \mu \mathrm{m}$. Tissue samples were then immersed in phosphate buffered saline with $0.2 \%$ Triton X-100 (PBST) and 5\% normal goat serum in PBST for $1 \mathrm{~h}$. Then incubated overnight at $4^{\circ} \mathrm{C}$ with primary mouse anti-TLR4 (ab22048; Abcam, 1:1,000) and anti-NF-kB (ab16502; Abcam, 1:1,000). The samples were then incubated for $2 \mathrm{~h}$ at room temperature in a moist environment with secondary antibody Alexa Fluor fluorescent 568 anti-mouse (ab175471; 1:200; Abcam).

Statistical analysis. All data are presented as the mean \pm standard deviation. Differences between groups were assessed using one-way analysis of variance and followed by Tukey's post-hoc test. $\mathrm{P}<0.05$ was considered to indicate a statistically significant difference.

\section{Results}

Sparstolonin B attenuates SCI-induced Batto, Beattie and Bresnahan $(B B B)$ score and water content in rats. Following treatment with sparstolonin $B$, the effects of sparstolonin B on the BBB score and water content of SCI rats were analyzed. As presented in Fig. 2, there were significant decrease in BBB score and an increase in the water content of spinal cord in the
SCI model group, compared with the control group. Treatment with sparstolonin B significantly recovered the decrease in $\mathrm{BBB}$ score and the increase in the water content of the spinal cord in SCI rats, compared with the SCI model group (Fig. 2).

Sparstolonin B attenuates the $m R N A$ expression of proinflammatory cytokines interleukin (IL-18, IL-6, IL-1 $\beta$ and $I L-23$ in SCI rats. Subsequently, the anti-inflammatory effects of sparstolonin B were analyzed in SCI rats. The expression levels of IL-18, IL-6, IL-1 $\beta$ and IL-23 were measured using RT-qPCR analysis. The IL-18, IL-6, IL-1 $\beta$, and IL-23 levels in SCI rats were increased compared with the control group (Fig. 3). Treatment with sparstolonin B significantly decreased IL-18, IL-6, IL-1 $\beta$ and IL-23 levels in SCI rats, compared with the SCI model group (Fig. 3).

Sparstolonin B attenuates the levels of TNF- $\alpha$ and IFN- $\gamma$ in $S C I$ rats. We determined TNF- $\alpha$ and IFN- $\gamma$ levels in SCI rat treated by Sparstolonin B using ELISA kits. As presented in Fig. 4, a significant increase was observed in TNF- $\alpha$ and IFN- $\gamma$ levels in the SCI model group, compared with the control group. Sparstolonin B significantly inhibited TNF- $\alpha$ and IFN- $\gamma$ expression in SCI rats, compared with the SCI model group (Fig. 4).

Sparstolonin B attenuates caspase-3 activity in SCI rats. The anti-apoptotic effects of Sparstolonin B were examined in SCI rats. Compared with the control group, caspase-3 activity in the SCI model group was significantly promoted (Fig. 5). The promotion of caspase-3 activity in SCI rats was significantly decreased by Sparstolonin B, compared with the SCI model group (Fig. 5).

Sparstolonin B attenuates the monocyte chemoattractant protein 1 (MCP1) mRNA level in SCI rats. The present study investigated the effects of Sparstolonin B on MCP1 mRNA expression in SCI rats, using RT-qPCR analysis. Fig. 6 demonstrates that the MCP1 mRNA level in the SCI model group was significantly increased compared with the control group. The increased MCP1 mRNA level in SCI rats was reversed by Sparstolonin B, compared with the SCI model group (Fig. 6).

Sparstolonin B attenuates Bax protein expression in SCI rats. The present study investigated the anti-apoptotic mechanism of Sparstolonin B in SCI; the Bax protein level was measured using western blot analysis. The results of the western blot analysis demonstrated that the Bax protein level in the SCI 

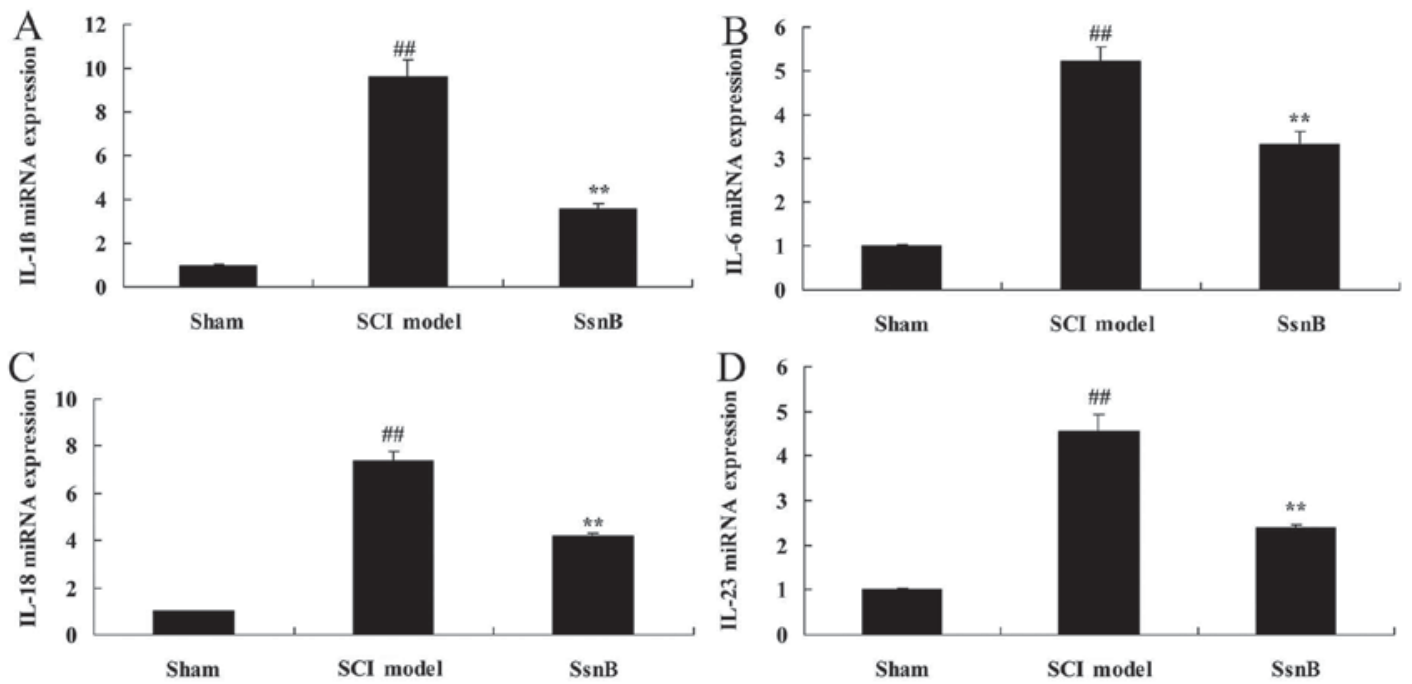

Figure 3. Sparstolonin B attenuates the mRNA expression of proinflammatory cytokines IL-18, IL-6, IL-1 $\beta$ and IL-23 in SCI rats. Sparstolonin B attenuated the mRNA expression of (A) IL-1 $\beta$, (B) IL-6, (C) IL-18 and (D) IL-23 in SCI rats. ${ }^{\# \#} \mathrm{P}<0.01$ vs. sham control group; ${ }^{* * *} \mathrm{P}<0.01$ vs. SCI model group. SsnB, sparstolonin B group; SCI, spinal cord injury; IL, interleukin.
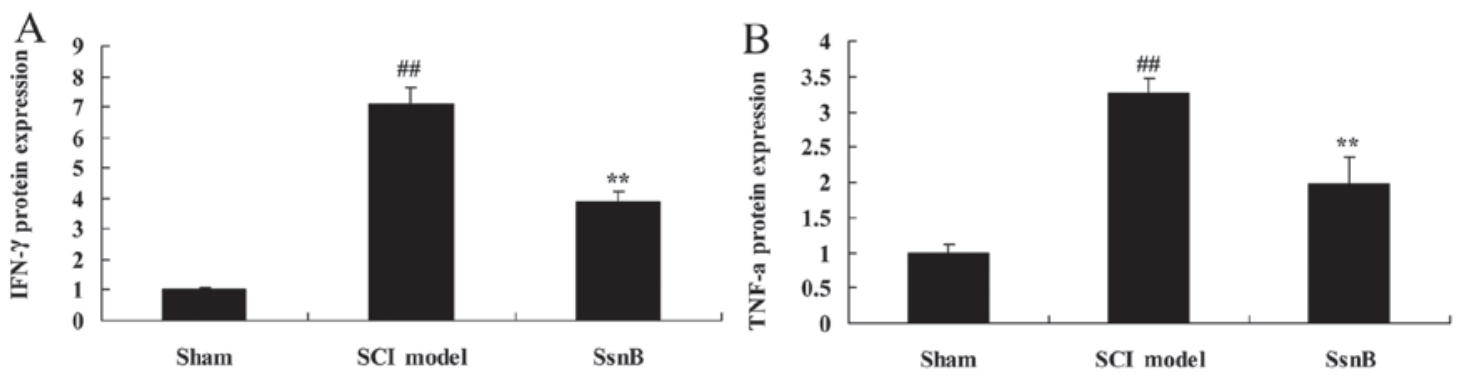

Figure 4. Sparstolonin B attenuates the levels of TNF- $\alpha$ and IFN- $\gamma$ in SCI rats. Sparstolonin B attenuated the expression of (A) TNF- $\alpha$ and (B) IFN- $\gamma$ in SCI rats. ${ }^{\# \#} \mathrm{P}<0.01$ vs. sham control group; ${ }^{* *} \mathrm{P}<0.01$ vs. SCI model group. SsnB, sparstolonin B group; SCI, spinal cord injury; IFN- $\gamma$, interferon- $\gamma$; TNF- $\alpha$, tumor necrosis factor- $\alpha$.

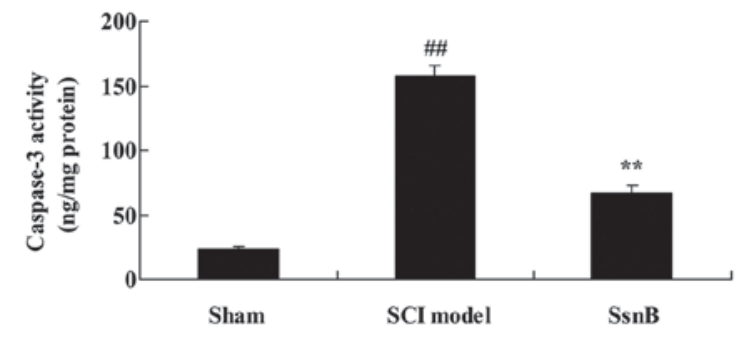

Figure 5. Sparstolonin B attenuates caspase-3 activity in SCI rats. ${ }^{\# \#} \mathrm{P}<0.01$ vs. sham control group; ${ }^{* *} \mathrm{P}<0.01$ vs. SCI model group. SsnB, sparstolonin B group; SCI, spinal cord injury.

model group was significantly upregulated, compared with the control group (Fig. 7). However, treatment with Sparstolonin B significantly suppressed Bax protein expression in SCI rats compared with the SCI model group (Fig. 7).

Sparstolonin B attenuates TLR4 MyD88 and NF- $\kappa B$ protein levels in SCI rat. In order to investigate the anti-inflammatory mechanism of Sparstolonin B in SCI, the TLR4 MyD88 and $\mathrm{NF}-\kappa \mathrm{B}$ signaling pathway was analyzed using western blot analysis and immunohistochemistry. As presented in Fig. 8,

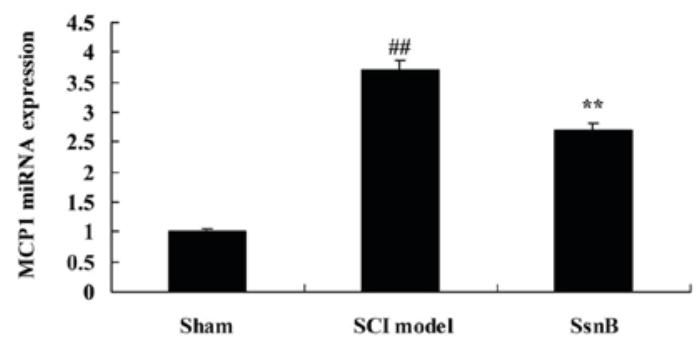

Figure 6. Sparstolonin B attenuates the MCP1 mRNA expression level in SCI rats. ${ }^{\# \#} \mathrm{P}<0.01$ vs. sham control group; ${ }^{* *} \mathrm{P}<0.01$ vs. SCI model group. $\mathrm{SsnB}$, sparstolonin B group; SCI, spinal cord injury; MCP1, monocyte chemoattractant protein 1 .

TLR4, MyD88 and NF- $\kappa$ B expression was significantly induced in the SCI model group, compared with the control group. Treatment with Sparstolonin B suppressed TLR4, MyD88 and NF- $\kappa$ B protein levels in SCI tissue compared with the SCI model group (Fig. 8).

\section{Discussion}

SCI is a common injury observed in spinal surgery. Generally, SCI is caused by transport accidents, falling, construction 

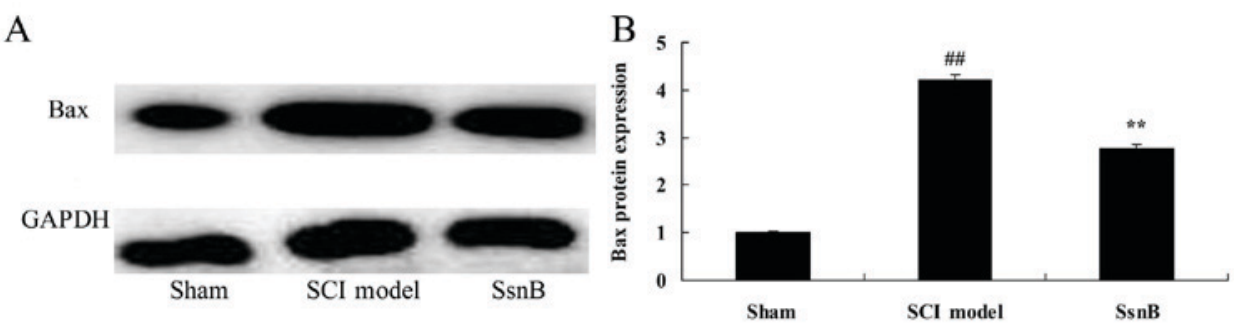

Figure 7. Sparstolonin B attenuates Bax protein level in SCI rats. Sparstolonin B attenuated the Bax protein expression level, as demonstrated using (A) western blotting and (B) statistical analysis, in SCI rats. ${ }^{\# \#} \mathrm{P}<0.01$ vs. sham control group; ${ }^{* *} \mathrm{P}<0.01$ vs. SCI model group. SsnB, sparstolonin B group; SCI, spinal cord injury; Bax, apoptosis regulator Bax.

A

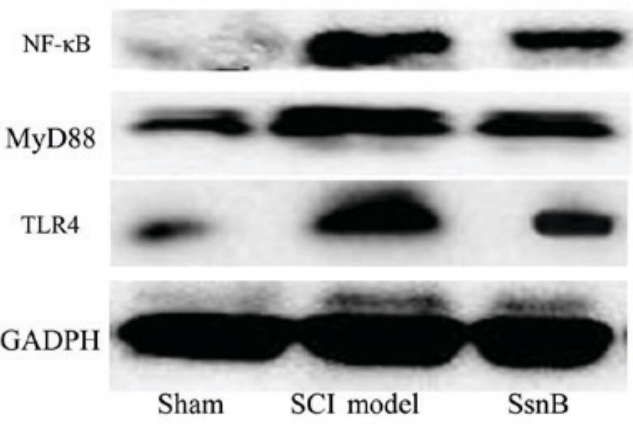

$\mathrm{C}$

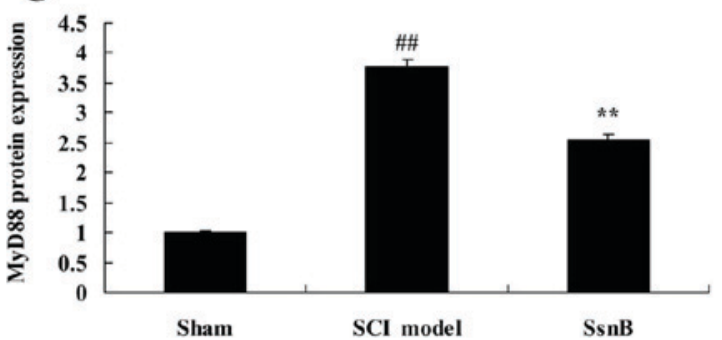

$\mathrm{E}$

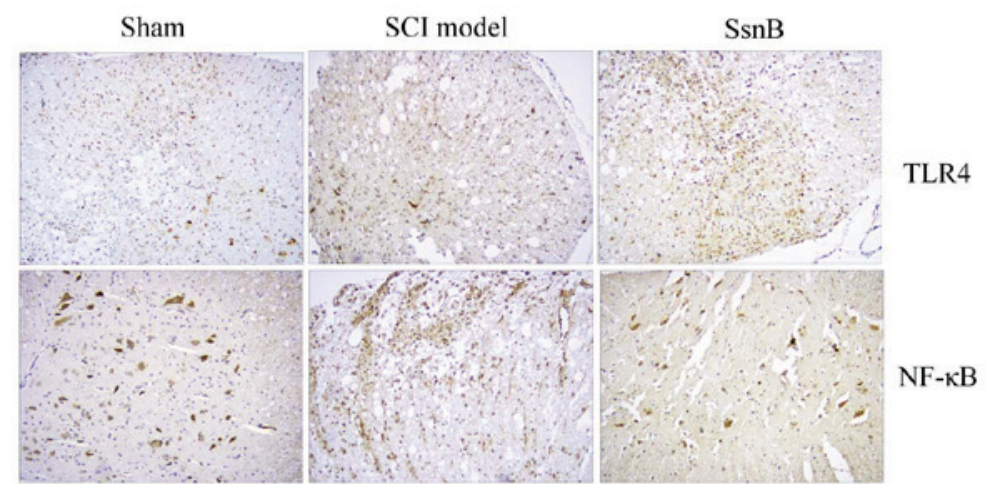

B
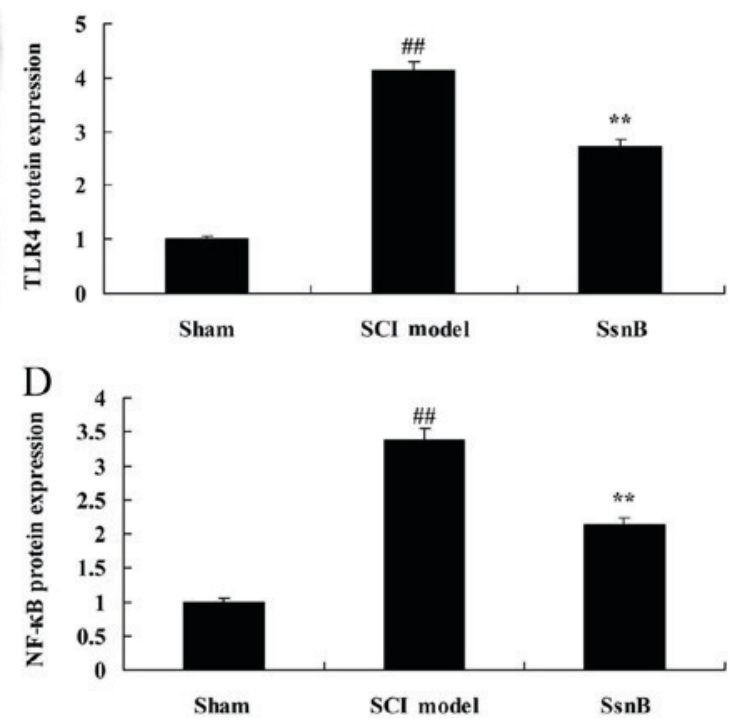

TLR4

$\mathrm{F}-\mathrm{kB}$

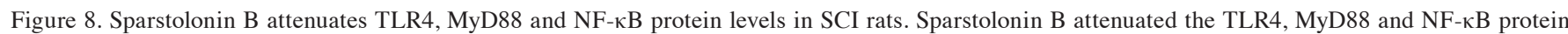
expression level, as demonstrated using (A) western blotting and statistical analysis of (B) TLR4, (C) MyD88 and (D) NF-kB protein level. (E) TLR4 and $\mathrm{NF}-\kappa \mathrm{B}$ protein levels were additionally analyzed using immunohistochemistry (magnification, $\mathrm{x} 5$ ). ${ }^{\# \#} \mathrm{P}<0.01$ vs. sham control group; ${ }^{* *} \mathrm{P}<0.01$ vs. SCI model

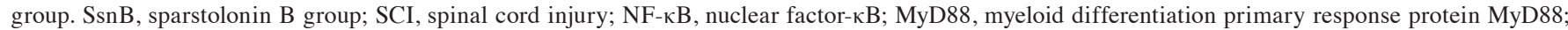
TLR4, Toll-like receptor 4 .

and industrial accidents, sports injuries and combat injury. In recent years, with the development of urban construction and the transportation industry, the incidence of acute SCI has been increasing annually (20). A previous epidemiological study demonstrated that $\sim 11,000$ new cases of acute SCI were reported in the USA each year (21). Acute SCI frequently causes a variety of complications, including respiratory dysfunction, respiratory failure, pneumonia, pulmonary edema, pulmonary embolism and other respiratory complications, which are the most commonly detected complications of SCI with an incidence rate of $67 \%$ (22). In addition, respiratory system complications contribute to the early mortality of patients, 
with a proportion $>20-50 \%$ (23). Although pre-hospital first aid and clinical therapy has received continuous innovation and improvement, early mortality from acute SCI caused by respiratory failure remains at a high level (23). The results of the present study indicated that sparstolonin B significantly recovered the decrease in $\mathrm{BBB}$ score and the increase in the water content of the spinal cord in SCI rat.

Inflammatory reactions are the primary cause of sequential damage associated with SCI, and inflammation is an important part of the acute SCI pathophysiological mechanism (24). SCI promotes a series of molecular biological events which lead to inflammatory cell activation, arising from circulatory system infiltration in spinal cord tissue, pro-inflammatory factors and neurotoxin release, and the generation of oxygen free radical and nitroso compounds which lead to cellular lesions (25). In the present study, it was demonstrated that sparstolonin B significantly decreased IL-18, IL-6, IL-1 $\beta$, and IL-23 levels, and TNF- $\alpha$ and IFN- $\gamma$ levels, in SCI rats. Liu et al (18) reported that sparstolonin B decreased vascular smooth muscle cell proliferation, migration and inflammatory responses.

Inflammatory reactions are predominantly regulated by gene expression. The NF- $\kappa \mathrm{B}$ family is the major regulatory factor for inflammatory gene expression, regulating the expression of numerous cytokines in central nervous system injury and controlling the inflammatory reactions (26). Abnormally-activated $\mathrm{NF}-\kappa \mathrm{B}$ may induce neuronal apoptosis (26). A previous study demonstrated that following SCI, abnormal activation of $\mathrm{NF}-\kappa \mathrm{B}$, colocalization of activated $\mathrm{NF}-\kappa \mathrm{B}$ and its target gene product inducible nitric oxide synthase (iNOS) may be observed (27). In traumatic SCI, the expression of a number of genes regulated by $\mathrm{NF}-\kappa \mathrm{B}$ has been detected, including proinflammatory cytokines TNF- $\alpha$, IL-1 $\beta$ and IL-6, MCP-1, adhesion molecules intercellular adhesion molecule 1 and vascular cell adhesion protein 1 , cyclooxygenase-2, iNOS, and matrix metalloproteinases (28). Direct inhibition of NF- $\mathrm{BB}$ activation may reduce the expression of such genes associated with inflammatory reactions following SCI, thereby relieving inflammation and improving functional recovery (29). Previous studies have demonstrated that the inhibition of NF- $\kappa \mathrm{B}$ alleviates inflammatory reaction in SCI $(30,31)$. The results of the present study demonstrated that sparstolonin $\mathrm{B}$ attenuated caspase-3 activity and Bax protein expression, and inhibited MCP1 mRNA expression, in SCI rats.

TLRs are type I transmembrane proteins. TLRs belong to a highly conservative pattern recognition receptor family, and are widely distributed on the surface of macrophages, monocytes, dendritic cells, natural killer cells and lymphocytes (32). The TLR family includes $\geq 12$ members, including TLR4 (33). TLR4 has been extensively studied due to its involvement in and mediation of inflammatory reactions (34). A previous study demonstrated that when the spinal cord is damaged, microglial cell are activated and inflammatory factors released (35); the expression of TLR4 and downstream signaling pathways serve roles in this process. During SCI, necrotic neurons release $60 \mathrm{kDa}$ heat shock protein mitochondrial and other endogenous ligands (36). In addition to the TLR4 on the cell surface and microglial cell activation, TLR4 is able to activate downstream signal transduction through the MyD88-dependent and MyD88 independent pathways, activate interferon regulatory factor $3, \mathrm{NF}-\kappa \mathrm{B}$ and other transcription factors, induce spinal cord inflammation, provoke an immune response, release an inflammatory medium and lead to spinal cord sequential injury, necrosis and apoptosis of nerve cells (34). Necrotic or apoptotic nerve cells release more endogenous ligands and continuously activate microglial cells, thus causing a cyclical effect. TLR4 signal pathway activation may lead to the activation of microglial cells. It has been observed that the MyD88 dependent-NF- $\kappa \mathrm{B}$ signaling pathway of microglial cells and the mitogen-activated protein kinase signaling pathway may be activated (36). Downstream inflammatory mediators may be released, leading to marked neuronal death (37). A previous study indicated that the activation of the microglial TLR4 signaling pathway lead to inflammatory reactions in the central nervous system, thereby causing apoptosis and necrosis of nerve cell (35). Additionally, the expression of microglial TLR4 may be upregulated (37).

The oxidative activity of neutrophil granulocytes and other inflammatory cells in the serum of patients with acute SCI has been demonstrated to be markedly increased (38). In addition, free radicals have been observed to be increased, $\mathrm{NF}-\kappa \mathrm{B}$ may be upregulated and the enzymatic activity of myeloperoxidase may be increased (39). In addition, a previous study demonstrated that the neuronal damage caused by SCI may lead to the generation and release of certain inflammatory factors or other proteins (40). These proteins may enter the circulation through the injured blood brain barrier to mediate systemic inflammatory responses and lead to SCI (40). Wang et al (33) suggested that sparstolonin B may decreased high fat diet-induced obesity in rats and inhibit lipopolysaccharide-induced cytokine production via TLR4 and NF- $\mathrm{B}$ expression in $3 \mathrm{~T} 3-\mathrm{L} 1$ adipocytes. The results of the present study demonstrated that sparstolonin B markedly suppressed TLR4, MyD88 and $\mathrm{NF}-\kappa \mathrm{B}$ protein expression in SCI tissues. Liang et al (31) reported that sparstolonin $\mathrm{B}$ may act as a selective TLR2 and TLR4 antagonist by blocking early intracellular events.

In conclusion, the present study demonstrated that sparstolonin B attenuated spinal cord injury-induced inflammation and apoptosis in rats by modulating TLR 4 trafficking. The results of the present study provided initial evidence that sparstolonin B exhibits the potential to serve as a therapeutic agent for protection against SCI.

\section{References}

1. Choi C, Rim B and Kim J: Development and evaluation of a assistive computer interface by SEMG for individuals with spinal cord injuries. IEEE Int Conf Rehabil Robot 2011: 5975386 , 2011.

2. Nussbaum EL, Flett H, Hitzig SL, McGillivray C, Leber D, Morris $\mathrm{H}$ and Jing $\mathrm{F}$ : Ultraviolet-C irradiation in the management of pressure ulcers in people with spinal cord injury: A randomized, placebo-controlled trial. Arch Phys Med Rehabil 94: 650-659, 2013.

3. Allison DJ and Ditor DS: Targeting inflammation to influence mood following spinal cord injury: A randomized clinical trial. J Neuroinflammation 12: 204, 2015.

4. Yang ML, Li JJ, Gao F, Du LJ, Zhao HP, Wang YM, Yang DG, Chen L, Liu HW, Yang HD, et al: A preliminary evaluation of the surgery to reconstruct thoracic breathing in patients with high cervical spinal cord injury. Spinal Cord 52: 564-569, 2014.

5. Ancha HR, Spungen AM, Bauman WA, Rosman AS, Shaw S, Hunt KK, Post JB, Galea M and Korsten MA: Clinical trial: The efficacy and safety of routine bowel cleansing agents for elective colonoscopy in persons with spinal cord injury- a randomized prospective single-blind study. Aliment Pharmacol Ther 30: 1110-1117, 2009. 
6. Celik EC, Erhan B, Gunduz B and Lakse E: The effect of low-frequency TENS in the treatment of neuropathic pain in patients with spinal cord injury. Spinal Cord 51: 334-337, 2013.

7. Apostolidis A, Thompson C, Yan X and Mourad S: An exploratory, placebo-controlled, dose-response study of the efficacy and safety of onabotulinumtoxin A in spinal cord injury patients with urinary incontinence due to neurogenic detrusor overactivity. World J Urol 31: 1469-1474, 2013.

8. Grossman RG, Fehlings MG, Frankowski RF, Burau KD, Chow DS, Tator C, Teng A, Toups EG, Harrop JS, Aarabi B, et al: A prospective, multicenter, phase I matched-comparison group trial of safety, pharmacokinetics, and preliminary efficacy of riluzole in patients with traumatic spinal cord injury. J Neurotrauma 31: 239-255, 2014

9. Yang ML, Li JJ, So KF, Chen JY, Cheng WS, Wu J, Wang ZM, Gao F and Young W: Efficacy and safety of lithium carbonate treatment of chronic spinal cord injuries: A double-blind, randomized, placebo-controlled clinical trial. Spinal Cord 50: 141-146, 2012.

10. Van Straaten MG, Cloud BA, Morrow MM, Ludewig PM and Zhao KD: Effectiveness of home exercise on pain, function, and strength of manual wheelchair users with spinal cord injury: A high-dose shoulder program with telerehabilitation. Arch Phys Med Rehabil 95: 1810-1817 e2, 2014

11. Lobenwein D, Tepeköylü C, Kozaryn R, Pechriggl EJ, Bitsche M, Graber M, Fritsch H, Semsroth S, Stefanova N, Paulus P, et al: shock wave treatment protects from neuronal degeneration via a toll-like receptor 3 dependent mechanism: Implications of a first-ever causal treatment for ischemic spinal cord injury. J Am Heart Assoc 4: e002440, 2015.

12. Freria CM, Bernardes D, Almeida GL, Simões GF, Barbosa GO and Oliveira AL: Impairment of toll-like receptors 2 and 4 leads to compensatory mechanisms after sciatic nerve axotomy. J Neuroinflammation 13: 118, 2016.

13. Li XQ, Lv HW, Tan WF, Fang B, Wang H and Ma H: Role of the TLR4 pathway in blood-spinal cord barrier dysfunction during the bimodal stage after ischemia/reperfusion injury in rats. J Neuroinflammation 11: 62, 2014.

14. Liang Q, Yu F, Cui X, Duan J, Wu Q, Nagarkatti P and Fan D Sparstolonin B suppresses lipopolysaccharide-induced inflammation in human umbilical vein endothelial cells. Arch Pharm Res 36: 890-896, 2013.

15. Liang Q, Dong S, Lei L, Liu J, Zhang J, Li J, Duan J and Fan D: Protective effects of Sparstolonin B, a selective TLR2 and TLR4 antagonist, on mouse endotoxin shock. Cytokine 75: 302-309, 2015.

16. Deng X, Zhang Y, Jiang F, Chen R, Peng P, Wen B and Liang J: The Chinese herb-derived Sparstolonin B suppresses HIV-1 transcription. Virol J 12: 108, 2015.

17. Zou NS, Liang QL, Li P, Liu J, Liu X, Kang A and Deng HS Determination of sparstolonin B by ultra-high performance liquid chromatography coupled with triple quadrupole mass spectrometry: Application to pharmacokinetic study of sparstolonin B in rat plasma. Biomed Chromatogr 29: 1486-1491, 2015.

18. Liu Q, Li J, Liang Q, Wang D, Luo Y, Yu F, Janicki JS and Fan D: Sparstolonin B suppresses rat vascular smooth muscle cell proliferation, migration, inflammatory response and lipid accumulation. Vascul Pharmacol 67-69: 59-66, 2015.

19. Darouiche RO, Al Mohajer M, Siddiq DM and Minard CG: Short versus long course of antibiotics for catheter-associated urinary tract infections in patients with spinal cord injury: A randomized controlled noninferiority trial. Arch Phys Med Rehabil 95: 290-296, 2014

20. Wadsworth BM, Haines TP, Cornwell PL, Rodwell LT and Paratz JD: Abdominal binder improves lung volumes and voice in people with tetraplegic spinal cord injury. Arch Phys Med Rehabil 93: 2189-2197, 2012.

21. Kim DI, Lee H, Lee BS, Kim J and Jeon JY: Effects of a 6-week indoor hand-bike exercise program on health and fitness levels in people with spinal cord injury: A randomized controlled trial study. Arch Phys Med Rehabil 96: 2033-2040 e1, 2015.

22. Kim Y, Jo SH, Kim WH and Kweon OK: Antioxidant and anti-inflammatory effects of intravenously injected adipose derived mesenchymal stem cells in dogs with acute spinal cord injury. Stem Cell Res Ther 6: 229, 2015.
23. Ak H, Gülsen İ, Karaaslan T, Alaca İ, Candan A, Koçak H, Atalay T, Çelikbilek A, Demir İ and Yilmaz T: The effects of caffeic acid phenethyl ester on inflammatory cytokines after acute spinal cord injury. Ulus Travma Acil Cerrahi Derg 21: 96-101, 2015

24. Hsieh SM, Wang YH, Chang SC and Huang TS: Low dose HIV-1 Tat improves the defective nuclear factor (NF)-kappaB activity of dendritic cells from persons with spinal cord injury. Cell Immunol 257: 105-110, 2009.

25. Chu LW, Chen JY, Wu PC and Wu BN: Atorvastatin prevents neuroinflammation in chronic constriction injury rats through nuclear NFKB downregulation in the dorsal root ganglion and spinal cord. ACS Chem Neurosci 6: 889-898, 2015.

26. Chengke L, Weiwei L, Xiyang W, Ping W, Xiaoyang P, Zhengquan X, Hao Z, Penghui Z and Wei P: Effect of infliximab combined with methylprednisolone on expressions of $\mathrm{NF}-\kappa \mathrm{B}$, TRADD, and FADD in rat acute spinal cord injury. Spine (Phila Pa 1976) 38: E861-E869, 2013.

27. Kang N, Hai Y, Yang J, Liang F and Gao CJ: Hyperbaric oxygen intervention reduces secondary spinal cord injury in rats via regulation of HMGB1/TLR4/NF- $\mathrm{KB}$ signaling pathway. Int J Clin Exp Pathol 8: 1141-1153, 2015.

28. Kuang X, Huang Y, Gu HF, Zu XY, Zou WY, Song ZB and Guo QL: Effects of intrathecal epigallocatechin gallate, an inhibitor of Toll-like receptor 4, on chronic neuropathic pain in rats. Eur J Pharmacol 676: 51-56, 2012.

29. Zhang YK, Liu JT, Peng ZW, Fan H, Yao AH, Cheng P, Liu L, Ju G and Kuang F: Different TLR4 expression and microglia/macrophage activation induced by hemorrhage in the rat spinal cord after compressive injury. J Neuroinflammation 10: 112, 2013.

30. Impellizzeri D, Ahmad A, Di Paola R, Campolo M, Navarra M, Esposito E and Cuzzocrea S: Role of Toll like receptor 4 signaling pathway in the secondary damage induced by experimental spinal cord injury. Immunobiology 220: 1039-1049, 2015.

31. Liang Q, Wu Q, Jiang J, Duan J, Wang C, Smith MD, Lu H, Wang Q, Nagarkatti P and Fan D: Characterization of sparstolonin B, a Chinese herb-derived compound, as a selective Toll-like receptor antagonist with potent anti-inflammatory properties. J Biol Chem 286: 26470-26479, 2011.

32. Xu JM, Tao LJ, Fu D, Lv ZP, Li L and Dai RP: Activation of interleukin-1 beta (IL-1 beta) signaling in the spinal cord in the rats with experimental cardiac injury. Int J Cardiol 128: 413-418, 2008

33. Wang M, Xiu L, Diao J, Wei L and Sun J: Sparstolonin B inhibits lipopolysaccharide-induced inflammation in 3T3-L1 adipocytes. Eur J Pharmacol 769: 79-85, 2015.

34. Xu C, Wu F, Mao C, Wang X, Zheng T, Bu L, Mou X, Zhou Y, Yuan G, Wang S and Xiao Y: Excess iodine promotes apoptosis of thyroid follicular epithelial cells by inducing autophagy suppression and is associated with Hashimoto thyroiditis disease. J Autoimmun 75: 50-57, 2016.

35. Raad H, Eskalli Z, Corvilain B, Miot F and De Deken X: Thyroid hydrogen peroxide production is enhanced by the Th2 cytokines, IL-4 and IL-13, through increased expression of the dual oxidase 2 and its maturation factor DUOXA2. Free Radic Biol Med 56: 216-225, 2013.

36. Lee J, Yi S, Kang YE, Chang JY, Kim JT, Sul HJ, Kim JO, Kim JM, Kim J, Porcelli AM, et al: Defective ciliogenesis in thyroid hurthle cell tumors is associated with increased autophagy. Oncotarget 7: 79117-79130, 2016.

37. Koc A, Batar B, Celik O, Onaran I, Tasan E and Sultuybek GK: Polymorphism of the NFKB1 affects the serum inflammatory levels of IL-6 in Hashimoto thyroiditis in a Turkish population. Immunobiology 219: 531-536, 2014.

38. Zhu P, Liao LY, Zhao TT, Mo XM, Chen GG and Liu ZM: GPER/ERK\&AKT/NF- $\kappa$ B pathway is involved in cadmium-induced proliferation, invasion and migration of GPER-positive thyroid cancer cells. Mol Cell Endocrinol 442: 68-80, 2017

39. Pringle DR, Vasko VV, Yu L, Manchanda PK, Lee AA, Zhang X, Kirschner JM, Parlow AF, Saji M, Jarjoura D, et al: Follicular thyroid cancers demonstrate dual activation of PKA and mTOR as modeled by thyroid-specific deletion of Prkarla and Pten in mice. J Clin Endocrinol Metab 99: E804-E812, 2014.

40. Xian H, Wang F, Teng W, Yang D and Zhang M: Thyroid hormone induce a p53-dependent DNA damage through PI3K/Akt activation in sperm. Gene 615: 1-7, 2017. 